\title{
Pedagogy training for the development of GTA mindsets and inclusive teaching practices
}

\author{
Caitlin Kepple, Marakee Tilahun, Natalia Matti, and Kim Coble \\ Department of Physics and Astronomy, San Francisco State University, 1600 Holloway Ave, San Francisco, CA, 94132
}

The Physics and Astronomy Department at a large, diverse, master's-granting university has recently implemented a pedagogy training course for graduate teaching assistants (GTAs). Using survey and interview testimonies from GTAs and other lab instructors over the course of three semesters, we identify potential areas of growth that can result from taking the pedagogy course. These areas include: developing a growth mindset and asset-based thinking, identifying the need for inclusive teaching practices, and implementing such practices. To help inform future pedagogy training courses, we have identified four personas that represent key archetypes of instructors that are likely to teach physics and astronomy labs. By cross-examining both sets of data, we have observed multiple areas that each persona is likely to develop as a result of training. We aim to use these results as evidence to further demonstrate the necessity for professional development for early career instructors. 


\section{INTRODUCTION}

\section{A. Background}

The physics education community has come to widely recognize the value and necessity for training graduate teaching assistants (GTAs) [1-3]. Previous work by Lee (2019) has shown that pedagogy training can shift GTAs' beliefs about teaching from "traditional" (instructorcentered) to more active learning oriented [4]. This positive shift was found to be especially true for inexperienced GTAs. However, many training courses for GTAs have little to no pedagogical components, and even fewer include explicit components that focus on equity and inclusion in STEM $[5,6]$. We hope to add to this dialogue by considering GTA mindsets about teaching that are based on themes of equity and inclusion both before and after training. As San Francisco State University (SFSU) is a Hispanic-serving institution with a diverse student population, we offer an important perspective on the current field of education research that is currently overpopulated with data from primarily white institutions [7]. GTAs will likely take on a variety of teaching and mentorship roles during their careers, regardless of industry. Therefore, we believe an emphasis on equitable teaching mindsets and practices is paramount in any training program for GTAs, as these skills will remain applicable throughout their career.

We characterize the term "mindsets" around the notion of instructors possessing a growth mindset [8-10] for themselves and their students, along with our own objective to include asset-based thinking [11] for students who come from a wide array of backgrounds. We define growth mindset similar to Dweck (2008) as having the belief that a person can cultivate and develop their intellectual ability through application and instruction [8]. In this context, an asset-based model of thinking (also coined as "funds of knowledge") is the idea of using accumulated cultural experiences as relevant knowledge and skills that are valued in the classroom community $[12,13]$, particularly by the instructor toward their students. Although these references make a distinction between the "asset model" and "funds of knowledge" terms, we do not believe our study goes into enough detail to require this distinction. Much of the education community has begun to widely accept these modes of thinking as more equitable for students $[14,15]$. Our pedagogy course (PC) maintains specific goals for GTAs to become familiar with and be able to implement inclusive teaching practices. Therefore, these mindsets (growth mindset and asset model) and course goals will act as our guide for analyzing the development of our GTAs as a result of the PC. For the remainder of this paper, the term PC will refer to the course offered for Physics and Astronomy GTAs each fall at SFSU.

\section{B. Institution, labs, and pedagogy course}

SFSU is a public, master's-granting university of approximately 30,000 students, designated as a Hispanicserving institution, and one of the most diverse large universities in the United States. Students who enroll in the lower division physics and astronomy labs are almost all non-physics majors. The department typically offers 50-60 lab sections of 20-30 students each semester. Slightly more than half of the labs are taught by GTAs, and the rest by lecturers (non-tenure track faculty) in the department.

The PC, first implemented in Fall 2018 and worth three elective credits, is now required for any graduate student who wishes to obtain a special departmental scholarship in addition to the university stipend for teaching a lab. The PC was initiated by the faculty co-author on this paper and is taught each fall semester. In terms of content, the course maintains explicit goals for GTAs to reflect on their teaching practice in order to develop a well-defined set of ideas about creating an inclusive classroom-and thus promote a sense of belonging for students. Each week, GTAs complete various readings for inclusive teaching methods and discuss them in class. Topics include (but are not limited to) sense of belonging, cultural wealth, and best practices for broadening participation in STEM by historically underrepresented groups $[11,14,16,17]$. GTAs also complete peer-observation assignments and a small action research project at the end of the semester.

We realize that pedagogy training for GTAs is still a growing effort for many university STEM departments. To that end, this paper will explore some of the benefits of implementing this type of training. We hope this will further highlight the value of professional development for inclusive teaching at all levels. Our primary research question is:

What areas of growth result from equity and inclusionbased pedagogy training for lab instructors with differing motivations for teaching?

\section{STUDY METHODS}

\section{A. Data collection: lab instructor surveys and interviews}

Over the course of three semesters (Spring 2018, Fall 2018, and Fall 2019), interviews and anonymous surveys were widely conducted with lab instructors in the department. As mentioned above, many of the labs are taught by lecturers, who often also teach one or more lecture courses. Our data also includes testimonies from lecturers, as we wish to understand how pedagogy training may benefit anyone teaching undergraduate labs.

We included both surveys and interviews for this study as a method for triangulating both the in-depth and large-scale details one might observe using the two techniques individually. Interviews were meant to offer a deeper level of insight from instructors, while surveys were meant to 
encourage wider participation across the department. In all, we surveyed approximately $62 \%$ of lab instructors over three semesters. We believe almost all instructors that we interviewed also filled out the survey. Below we will discuss the interviews and surveys in more detail.

We collected 14 interviews in total-three from lecturers, and 11 from GTAs. To recruit participants, we sent out a general invitation each semester to all lab instructors to volunteer. The interviews were conducted in a semistructured format, and largely focused on the lab instructors' motivations for teaching, previous teaching experience, prior/current training, teaching practices, and thoughts about what the future PC might look like. This study was designed to be exploratory in nature, thus the interview topics were broader than the particular research question addressed in this paper. On average, interviews lasted about 30-45 minutes, and were audio-recorded only. Interviews were transcribed by a total of three researchers along with three interviews transcribed using the Zoom transcription feature.

Surveys were collected online via Qualtrics and asked almost identical questions to the interviews. Participants filled out each question in free-response format, with questions grouped by general topics. Through a combination of volunteer responses and responses based on participation credit in the PC, we collected a total of 37 responses, mainly from GTAs (about 5 from lecturers). Each semester, the survey was conducted during the last week of classes so that each respondent had taught at least one semester of lab at that point. Spring 2018 responses were collected before training had been implemented $(\mathrm{N}=10)$, Fall 2018 responses came predominantly from those who were in the PC $(\mathrm{N}=11)$, and Fall 2019 respondents had all taken the $\mathrm{PC}(\mathrm{N}=16)$. We are aware of a small number of GTAs who took the survey both pre and post training, though most participants only took the survey once as either pre/post training.

For both sets of data, researchers on the project highlighted the phrases from instructors that directly answered each question being asked (in the event that the conversation went off on a tangent). Each researcher also had the opportunity to highlight any additional text that was thought to directly relate to the participants' attitudes or methods for inclusive teaching. This was done to ensure consistency of analysis between interviews and surveys.

\section{B. Analysis: Potential areas for instructor growth}

Our initial analysis was guided by the mindset frameworks discussed in the introduction. The first three categories in our analysis include growth/fixed mindsets, both in terms of having this mindset toward their students (GM-Student) and in terms of themselves as instructors (GM-Instructor), as well as asset/deficit models toward students (Asset Model).

We were also interested in whether the lab instructors were thinking about inclusive teaching while in the classroom, and whether they acted on those thoughts. Accordingly, we also created categories for lab instructors' equity practices in lab.
Based on whether instructors felt they were thinking and acting equitably, we added two final categories that correspond to whether they acknowledge the need for inclusive teaching methods (Familiarity), and whether instructors feel they implement any methods specifically for the purpose of inclusivity (Implementation).

Following the beginning stages for instrument development using mixed data [18], phrases of instructor responses were rated on a five-point scale for each of the five categories by the first author of this article and discussed with the faculty co-author. The cases of growth/fixed mindset and asset/deficit model were based on literature definitions[8-11] whereas familiarity and implementation were developed from the data itself. That is - the lower and upper limits of familiarity and implementation were emergent from testimonies by lab instructors. Intermediate ratings were used if the respondent only slightly favored one approach over the other. For example: if an instructor included a mixture of statements regarding both a fixed and growth mindset toward their students, but had a slight majority of growth-oriented statements, we would score this as a 4 . Cases where the respondent spoke about the topic but remained neutral received a rating of 3 . Categories where the instructor did not show any particular stance at all were not assigned a value.

\section{Analysis: Personas}

According to Wheeler et al. (2019), GTAs' motivations for teaching can be informed by their prior experiences, teaching beliefs, and teaching confidence [19]. Over time we began to observe variations between instructors' motivations for teaching and how they scored in each category. We wanted to acknowledge the rich personalities of our GTAs while also observing their potential for growth as instructors. To address this, we employed similar methods to that of Madsen et al. [14] by identifying a set of "personas" that represent an overall trend in instructors' behavior. For us, this behavior was based on instructors' motivations for teaching. This offered consistent categorization (based on instructors' motivations to teach), while enabling us to observe changes in their mindsets and teaching practices as a result of the PC. Therefore, we use personas as a way to express similar characteristics of instructors that represent key archetypes for the makeup of future classes of the PC [14].

A persona classification was assigned to each respondent according to their motivations for teaching, and then assigned either "pre" or "post" according to their response of whether they took the PC or not. We integrated this pre/post classification in order to identify any shifts that were a direct result of the $\mathrm{PC}$.

\section{RESULTS \& DISCUSSION}

We identified four personas from our dataset, which we believe encompass the four common types of GTAs and/or 
TABLE 1. Mindsets and equity practices by persona from lab instructor interview and survey data. Survey sample sizes are listed as the maximum number of participants, as participants were not counted if they did not comment on a given category.

\begin{tabular}{|c|c|c|c|c|c|c|c|c|}
\hline \multirow[b]{2}{*}{ Interviews } & \multicolumn{2}{|c|}{$\begin{array}{c}\text { Joel the Passive } \\
\text { Scholar }\end{array}$} & \multicolumn{2}{|c|}{$\begin{array}{c}\text { Sebastian the } \\
\text { Motivated Novice }\end{array}$} & \multicolumn{2}{|c|}{$\begin{array}{l}\text { Mariela the } \\
\text { Empathizer }\end{array}$} & \multicolumn{2}{|c|}{$\begin{array}{c}\text { Alexis the } \\
\text { Experienced Seeker }\end{array}$} \\
\hline & Pre $(N=2)$ & Post $(\mathrm{N}=1)$ & Pre $(\mathrm{N}=2)$ & Post $(\mathrm{N}=2)$ & Pre $(\mathrm{N}=1)$ & Post $(\mathrm{N}=2)$ & Pre $(\mathrm{N}=2)$ & Post $(\mathrm{N}=2)$ \\
\hline GM-Students & 1.0 & 3.0 & 3.5 & 3.0 & 5.0 & 4.5 & 3.5 & 5.0 \\
\hline GM-Instructor & 2.5 & 4.0 & 4.0 & 3.5 & 4.0 & 4.0 & 3.0 & 5.0 \\
\hline Asset Model & 1.0 & 2.0 & 3.0 & 3.0 & 5.0 & 5.0 & 3.5 & 4.5 \\
\hline Familiarity & 1.0 & 2.0 & 2.0 & 3.0 & 3.0 & 3.5 & 4.0 & 5.0 \\
\hline Implementation & 1.5 & 2.0 & 2.5 & $3.0=$ & 4.0 & 2.5 & $3.5=$ & 5.0 \\
\hline Surveys & Pre $(\mathrm{N}=5)$ & Post $(\mathrm{N}=8)$ & Pre $(\mathrm{N}=2)$ & Post $(\mathrm{N}=7)$ & Pre $(\mathrm{N}=3)$ & Post $(\mathrm{N}=5)$ & Pre $(\mathrm{N}=2)$ & Post $(\mathrm{N}=4)$ \\
\hline GM-Students & 2.0 & 3.2 & 3.0 & 4.1 & 4.0 & 4.4 & 2.5 & 4.7 \\
\hline GM-Instructor & 2.4 & 3.3 & 3.5 & 4.1 & 5.0 & 4.6 & 4.0 & 4.5 \\
\hline Asset Model & 1.5 & 3.7 & 3.5 & 3.7 & 4.0 & 4.2 & 3.0 & 4.3 \\
\hline Familiarity & 1.8 & 2.9 & 2.5 & 3.9 & 3.0 & 5.0 & 4.0 & 4.5 \\
\hline Implementation & 1.6 & 2.9 & 3.0 & 3.6 & 2.0 & 4.2 & 4.0 & 4.3 \\
\hline
\end{tabular}

lecturers who teach labs in the department and would likely take the PC. Each response that was categorized into a particular persona had the same primary reason for becoming a lab instructor, although the secondary reason was not always the same. In the case where the secondary reason was different, we chose the most popular among all responses for that persona. Two of these personas have similar short descriptive titles to Madsen et al., though the defining characteristics for all personas were emergent from the data. The genders of the personas do not necessarily reflect the genders of actual GTAs and lecturers in the department.

One of the most common GTA personas is Sebastian the Motivated Novice, who is motivated through his own interest to teach and/or positive experiences as a student himself. Alexis the Experienced Seeker is motivated by her knowledge (from experience) that teaching is something she enjoys and wants to continue; she is also a persona that is reserved for lecturers or very experienced GTAs. Joel the Passive Scholar has motivations to teach that are largely financial, with little interest otherwise. In the case of listing a secondary reason, many GTAs who fit this persona also cited the fact that teaching would help them strengthen their own knowledgebase. Mariela the Empathizer has reasons for teaching labs that are also for practical reasons (financial support/relevant to future work/solidifies content knowledge), however these reasons are almost always matched with the desire to teach because she knows it is something she will enjoy. One other important reason that came up fairly often for those GTAs that fit the Mariela persona is that they wish to enact change in the current field of physics either in terms of representation or to be an ally for students who are experiencing challenges to their sense of belonging.

Table 1 summarizes the averaged results from the lab instructor interview and survey data, shown in the form of a heat map. GM-Students corresponds to the instructor exhibiting growth mindset (GM) with respect to students' skills, and GM-Instructor is with respect to their own skill as an effective lab instructor. The other categories summarize instructors' expressions of an asset model of thinking, familiarity with the need for inclusive teaching, and demonstration of implementing inclusive teaching methods. There were some cases for the survey in which the respondent didn't address the topic at all, thus the sample size values listed are a maximum (rather than absolute). Because we did not conduct as many interviews as we had survey responses, some interview-based personas in Table 1 are represented by only one person. However, because the interviews went much more in-depth than the surveys, we were reasonably confident in assigning final scores for interviews.

In most cases we observe a shift in each persona from pre to post-PC. Although some personas appear to experience more growth than others, one must keep in mind that each persona is independent of the others and they are not meant to be compared to one another (as in real life we refrain from comparing one instructor to the next). The boxes with gray diagonal stripes are those where the individual participant scores deviated by more than one point when computing the average. With such limited sample sizes, these scores are not meant to be taken at face value, but rather to demonstrate areas of growth we observe for each persona.

In terms of individual personas, we notice that Joel and Alexis both stand to gain quite a bit from the PC. Conversely, it is also quite clear that both come into the course with extremely different mindsets about teaching, ideas about the need for equitable teaching, and how to implement such practices. Sebastian and Mariela seem to be more limited in growth across the categories. We see in Table 1 that Mariela scored fairly high in many categories pre-PC, thus there is less room for growth overall. For Sebastian we suspect possibly a combination of the desire to stick to skills he already knows (from positive experiences as an undergraduate) or possibly leaving the pedagogy class with less confidence in his skills (when realizing he needs more teaching experience). 
Table 2. Key identifying characteristics and potential areas of growth for each persona

\begin{tabular}{|c|c|c|c|}
\hline Persona & Reasons for becoming a lab instructor & Propensity for inclusive teaching & Likely areas for growth \\
\hline $\begin{array}{l}\text { Joel the Passive } \\
\text { Scholar }\end{array}$ & $\begin{array}{l}\text { Primary: Financial support } \\
\text { Secondary: Desire to strengthen their } \\
\text { own knowledge base }\end{array}$ & $\begin{array}{l}\text { - Many times unaware of the need for } \\
\text { inclusive teaching practices } \\
\text { - Often does not believe equity issues are } \\
\text { present in their classroom }\end{array}$ & $\begin{array}{r}\rightarrow \text { GM - Students } \\
\rightarrow \text { GM - Instructor } \\
\rightarrow \text { Asset Model } \\
\rightarrow \text { Familiarity } \\
\rightarrow \text { Implementation }\end{array}$ \\
\hline $\begin{array}{l}\text { Sebastian the } \\
\text { Motivated } \\
\text { Novice }\end{array}$ & $\begin{array}{l}\text { Primary: Interest in teaching as a } \\
\text { personal growth opportunity, enjoys } \\
\text { sharing their knowledge of the subject } \\
\text { Secondary: Financial benefit }\end{array}$ & $\begin{array}{l}\text { - Understands the need for equity, often } \\
\text { comes in with ideas of how to address it } \\
\text { - Often draws on positive experiences as } \\
\text { an undergraduate student }\end{array}$ & $\begin{array}{r}\text { GM - Students } \\
\text { GM - Instructor } \\
\rightarrow \text { Asset Model } \\
\rightarrow \text { Familiarity } \\
\rightarrow \text { Implementation }\end{array}$ \\
\hline $\begin{array}{l}\text { Mariela the } \\
\text { Empathizer }\end{array}$ & $\begin{array}{l}\text { Primary: Mix of practical reasons. E.g. } \\
\text { Financial support, relevant experience, } \\
\text { solidifies content knowledge } \\
\text { Secondary: Enjoys teaching }\end{array}$ & $\begin{array}{l}\text { - Uses empathy for students as a driver for } \\
\text { inclusive teaching } \\
\text { - May have prior lived experience with } \\
\text { equity issues }\end{array}$ & $\begin{array}{r}\text { GM - Students } \\
\text { GM - Instructor } \\
\rightarrow \text { Asset Model } \\
\rightarrow \text { Familiarity } \\
\text { Implementation }\end{array}$ \\
\hline $\begin{array}{l}\text { Alexis the } \\
\text { Experienced } \\
\text { Seeker }\end{array}$ & $\begin{array}{l}\text { Primary: Interest in teaching, usually } \\
\text { from extensive prior experience } \\
\text { Secondary: Wants to interact with } \\
\text { students }\end{array}$ & $\begin{array}{l}\text { - Recognizes need through experience } \\
\text { with teaching }\end{array}$ & $\begin{array}{l}\rightarrow \text { GM - Students } \\
\rightarrow \text { GM - Instructor } \\
\rightarrow \text { Asset Model } \\
\rightarrow \text { Familiarity } \\
\rightarrow \text { Implementation }\end{array}$ \\
\hline
\end{tabular}

Table 2 is a comprehensive summary of our observations for each persona. It includes their primary and secondary reasons for becoming a lab instructor, propensity for inclusive teaching, and where we observe consistent development for each as a result of the PC (marked with an arrow). These areas of growth are based on data from Table 1 -where each persona either showed improvement in the score in both interviews and surveys or improved in one but stayed constant in the other. Cases where the persona decreased in score from pre to post-PC (in either dataset) were left unmarked.

Here we again see that both Joel and Alexis appear to improve their score in every category, while gains for Sebastian and Mariela are more limited across the categories. This is not assumed to be good or bad; we would simply like to offer this as a tool to inform future pedagogy classes in how this type of training can benefit lab instructors with a variety of motivations for teaching.

\section{FUTURE WORK AND CONCLUSIONS}

We plan to continue analysis of the methods discussed by GTAs and lecturers that emphasize equitable and inclusive teaching in lab. These may be confirmed by future in-class observations to compare the alignment of GTAs' beliefs with practices, as previous literature has shown the two do not always align [20,21]. We plan to eventually compare these results to student testimonies about their sense of belonging and perceptions of the lab instructor and the lab environment. In this way we hope to keep the focus of teaching labs on students - especially those who are most marginalized in the STEM community in higher education.

Our goal for this paper was to present a number of areas for growth that we have observed in GTAs' mindsets and ideas about inclusive teaching, particularly in physics and astronomy labs. Through the use of interview and survey data, we have demonstrated likely areas where each "archetype" of lab instructor could develop as a result of an equity and inclusion-based pedagogy course. We found personas that are based on instructors' teaching motivations are useful tools in understanding the large-scale impacts of a pedagogy course. Although it is clear that some instructors may experience "more growth" in their skills than others, we see multiple areas of development for each persona. Our results also indicate that pedagogy training can be beneficial for instructors that are both experienced and inexperienced in the case of Alexis and Joel, respectively. Overall, we believe these areas of development demonstrate that pedagogy training is both beneficial and necessary for creating a welcoming classroom environment for all.

\section{ACKNOWLEDGMENTS}

The development of this project has been primarily supported by SF BUILD. SF BUILD is funded by the NIH Common Fund Linked grants: UL1 GM118985, TL4 GM118986, and RL5118984. Additional funding support has been provided by San Francisco State University. 
[1] Scherr R E and Stetzer M R 2016 Editorial: Focused Collection: Preparing and Supporting University Physics Educators Phys. Rev. Phys. Educ. Res. 12 1-3

[2] Jossem E L 2000 Resource Letter EPGA-1: The education of physics graduate assistants Am. J. Phys. $68502-12$

[3] Chini J J and Al-Rawi A 2013 Alignment of TAs' beliefs with practice and student perception AIP Conf. Proc. 1513 98-101

[4] Lee S W 2019 The impact of a pedagogy course on the teaching beliefs of inexperienced graduate teaching assistants CBE Life Sci. Educ. 18 1-12

[5] Schussler E E, Read Q, Marbach-Ad G, Miller K and Ferzli M 2015 Preparing biology graduate teaching assistants for their roles as instructors: An assessment of institutional approaches CBE Life Sci. Educ. 14 111

[6] Nicklow J W, Marikunte S S and Chevalier L R 2007 Balancing pedagogical and professional practice skills in the training of graduate teaching assistants J. Prof. Issues Eng. Educ. Pract. 133 89-93

[7] Kanim S and Cid X C 2017 The demographics of physics education research Phys. Rev. Phys. Educ. Res. 1620106

[8] Dweck C S 2008 Mindsets and Math / Science Achievement Oppor. Equ. Transform. Math. Sci. Educ. Citizsh. Glob. Econ. 1-17

[9] Aguilar L, Walton G and Wieman C 2014 Psychological insights for improved physics teaching Phys. Today 67 43-9

[10] Heggart K 2015 Developing a Growth Mindset in Teachers and Staff | Edutopia 1-5

[11] Yosso T J 2005 Whose culture has capital? A critical race theory discussion of community cultural wealth Race Ethn. Educ. 8 69-91
[12] Moll L C, Cathy A, Neff D and Gonzale N 1992 Funds of Knowledge for Teaching: Using a Qualitative Approach to Connect Homes and Classrooms Theory Pract. 31 132-41

[13] Verdin D, Godwin A and Capobianco B 2016 Systematic review of the funds of knowledge framework in STEM education ASEE Annu. Conf. Expo. Conf. Proc. 2016-June

[14] Estrada M, Eroy-Reveles A and Matsui J 2018 The Influence of Affirming Kindness and Community on Broadening Participation in STEM Career Pathways Physiol. Behav. 176 139-48

[15] De Grandi C, Ramos R and Mochrie S G J 2018 Assessment of strategies to build a welcoming STEM classroom environment for all students Phys. Educ. Res. Conf. Proc. 2018 3-6

[16] Steele C M 1997 A threat in the air (stereotype threat) 52 613-29

[17] Cheryan S, Plaut V C, Davies P G and Steele C M 2009 Ambient Belonging: How Stereotypical Cues Impact Gender Participation in Computer Science $J$. Pers. Soc. Psychol. 97 1045-60

[18] Onwuegbuzie A J, Bustamante R M and Nelson J A 2010 Mixed research as a tool for developing quantitative instruments J. Mix. Methods Res. 4 56-78

[19] Wheeler L B, Chiu J L, Maeng J L and Bell R L 2019 An exploratory study of teaching assistants' motivation for inquiry-based teaching in an undergraduate laboratory context Chem. Educ. Res. Pract. 20 53-67

[20] Kim M 2014 A Comparison of Pedagogical Practices and Beliefs in International and Domestic Mathematics Teaching Assistants 4 74-88

[21] Spike B T and Finkelstein N D 2013 Applying a framework for characterizing physics teaching assistants' beliefs and practices AIP Conf. Proc. 1513 394-7 